\title{
Spread of phasic muscle reflexes in normal and spastic subjects
}

\author{
J. W. LANCE AND P. DE GAIL ${ }^{1}$ \\ From the Division of Neurology, The Prince Henry Hospital, Sydney, and the School of Medicine, University \\ of New South Wales, Australia
}

When tendon jerks are elicited in patients with upper motor neurone lesions, and in some normal subjects with brisk reflexes, it is often observed that muscles remote from the point of percussion will contract, apparently simultaneously with the muscle whose tendon is percussed. A blow to the tendo Achillis frequently produces contraction of the hamstrings together with the triceps surae. Occasionally the quadriceps on the same side, or thigh adductors and knee flexors of the opposite side, may also respond. Lombard (1889) noted that the hamstrings muscles frequently contracted at the same time as the quadriceps when the knee jerk was obtained. In the upper limb, percussion of the radius commonly produces contraction of the biceps as well as the brachioradialis. The pectoralis major, triceps, and finger flexors may also contract in susceptible subjects. Similar multiple responses in the upper limb may be elicited by a blow to the pectoralis major insertion at the upper end of the humerus, to the ipsilateral clavicle and, rarely, to the sternum or contralateral clavicle. This irradiation or spread of reflexes has been accepted by clinicians as a manifestation of hyper-reflexia without its mechanism being generally understood, but a similar phenomenon in the spinal animal attracted the attention of Sherrington (1898).

Sherrington found that the 'cross knee-jerk' and 'cross adductor' reflex persisted after complete longitudinal splitting of the spinal cord, but were abolished by section of the dorsal roots on the side of the reflex, i.e., the side contralateral to the blow given. He referred to the work of Waller and Prevost who, in 1881, suggested that transmission of mechanical vibration or 'jar' to the muscle or its motor nerve was responsible for such contralateral reflexes. Sherrington considered it more likely that the jar excited afferent nerve fibres of muscles at, or just peripheral to, the dorsal root ganglion.

For purposes of description in this paper, we shall use the term 'direct' reflex when muscle contraction is caused by a blow to its own tendon, and in-

${ }^{1}$ Merck, Sharp and Dohme research fellow. direct' reflex when the initiating blow is at some point $\widehat{\Phi}$ remote from the muscle or its tendon.

The monosynaptic pathway of direct reflexes has been well established by animal experimentation. $\stackrel{\circ}{\circ}$ A sudden muscle stretch, as little as $8 \mu$ in the $\overrightarrow{\overrightarrow{\dot{ }}}$ decerebrate animal (Denny-Brown and Liddell, $\stackrel{\sim}{\mathscr{\omega}}$ 1927), causes discharge of primary, mostly nuclear bag, receptors of the muscle spindle which set up a synchronous volley of impulses in fast-conducting $\underset{\infty}{\sim}$ afferent fibres of the muscle nerve which synapse $\rightarrow$ with alpha motor neurones in the anterior horn of $w$ the spinal cord. It is probable that the "tendon jer砱 in man, and the equivalent $\mathrm{H}$ reflex produced b electrical stimulation of afferent fibres, employs $\frac{3}{2}-$ monosynaptic pathway under normal circumstances $?$ (Magladery, Porter, Park, and Teasdall, 1951), and 을 this is supported by the demonstration of pos? tetanic potentiation of the reflex in man (Hagbart 1962).

The pathway of indirect reflexes in man has not been established as far as we are aware. Possibilities which we considered were:-

1 That afferent fibres arising from spindles of the muscle primarily stimulated establish synaptic $\frac{\varnothing}{\varnothing}$ connexion via collaterals with anterior horn cells $\propto$ of synergistic, antagonistic, or contralateral muscle $\overrightarrow{0}$ groups.

2 That fibres from sources other than muscle spindles in the vicinity of percussion of the limb, e.g., Golgi tendon organs, receptors in periosteum or joints, form the afferent limb of the reflex arc.

3 That a vibration or stretch stimulus is trans- $\frac{0}{3}$ mitted mechanically through the body to receptors in the muscle whose contraction comprises the indirect reflex, and the pathway is thus the monosynaptic arc of the muscle concerned.

4 That a mechanical stimulus produces muscle contraction without the intervention of a reflex arc.

\section{PATIENTS AND METHODS}

Four normal subjects with brisk reflexes and 16 patients $N$ with upper motor neurone lesions affecting the limbs were $\mathcal{E}$ 
studied. Patients lay prone for study of hamstring reflexes, and supine for study of upper limb reflexes. Paired surface solder electrodes, applied over the muscle, recorded the compound action potential or electromyogram (E.M.G.) of the reflex. The vibration wave set up by percussion was recorded on the skin between the E.M.G. electrodes by a phonograph pickup cartridge containing a piezoelectric crystal.

Displacement of a limb following impact was measured by a Philips inductive displacement transducer, coupled with a direct-reading measuring bridge.

Reflex E.M.G., vibration wave, and displacement were simultaneously displayed, after amplification, on a Tektronix storage oscilloscope (type 564) equipped with a plug-in unit that provided four recording channels, using a time base of 1 to $10 \mathrm{msec} . / \mathrm{cm}$., and photographed with a Polaroid camera.

The oscilloscope trace was triggered by impact of a rubber reflex hammer, carrying a pair of copper contacts, with thin aluminium foil strapped to the skin at the site of percussion.

In three subjects the hamstrings jerk was elicited by a blow on the ligamentum patellae with the patient prone, the limb being rigidly clamped with the knee at a right angle. The spring-loaded pin of the displacement transducer impinged against the tibial border $10 \mathrm{~cm}$. distal to the tibial tuberosity (Fig. 4). Any movement of the limb away from the transducer, indicating knee flexion and thus shortening of the hamstrings, was shown on the oscilloscope as a downward deflection. Calibration was such that $0.2 \mathrm{~mm}$. displacement was equivalent to $1 \mathrm{~cm}$. on the screen.

Ischaemia of the distal part of a limb was attained using a sphygmomanometer cuff inflated to a pressure of 200 $\mathrm{mm}$. $\mathrm{Hg}$ for 30 to 50 minutes, a period sufficient to pro- duce distal loss of voluntary power and tendon reflexes, and diminution of all sensory modalities with relative sparing of pain and temperature sensibility. It has been shown that ischaemia of a nerve trunk first blocks the large diameter fibres of high conduction velocity and last of all the small fibres subserving pain (Lewis, Pickering, and Rothschild, 1931 ; Magladery, McDougal, and Stoll, 1950).

At other times, tendon reflexes were reduced or abolished without significant loss of voluntary power by infiltration of the muscle belly with 10 to $20 \mathrm{ml}$. of $1 \%$ procaine solution. This differential effect of procaine is mediated by selective blockade of gamma efferent fibres to the muscle spindle, leaving conduction relatively unimpaired in group 1A afferent and alpha motor fibres. The sensitivity of the spindle drops markedly when it is thus de-efferented, resulting in depression of tendon reflexes (Matthews and Rushworth, 1957 a, b; Rushworth, 1960).

To avoid misleading results caused by field spread of action potentials from adjacent muscle groups, it was required that a reflex contraction in the muscle concerned be clinically obvious during the experiment, so that reliance was not placed solely on E.M.G. recordings.

\section{RESULTS}

SPREAD OF REFLEXES All normal subjects or patients in this study exhibited multiple indirect reflexes as described in the introduction.

The reflex most commonly examined was the indirect hamstrings jerk. The latency of the hamstrings jerk when obtained directly by tapping the hamstrings tendons varied in 10 subjects from 20.0 to

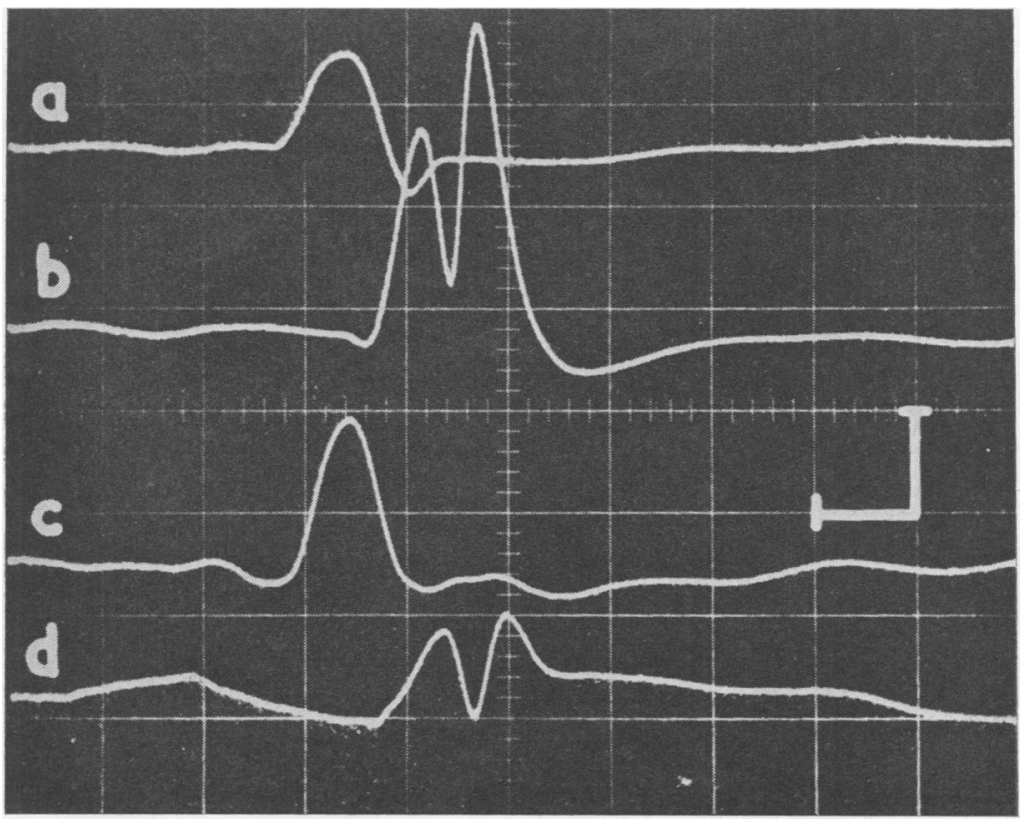

FIG. 1. Procaine infiltration of triceps surae, showing diminution of ankle jerk with preservation of indirect hamstrings jerk, $a$ and $b$, E.M.G. of hamstrings and triceps surae elicited by tapping tendo Achillis before procaine infiltration, $c$ and $d$, E.M.G. of above muscles after infiltration of gastrocnemius with $20 \mathrm{ml}$. procaine $1 \%$. Calibration: Vertical = $0.2 \mathrm{mV}$ for $a$ and $c ; 0.5 \mathrm{mV}$ for $b$ and $d$. Horizontal $=$ 10 msec. 


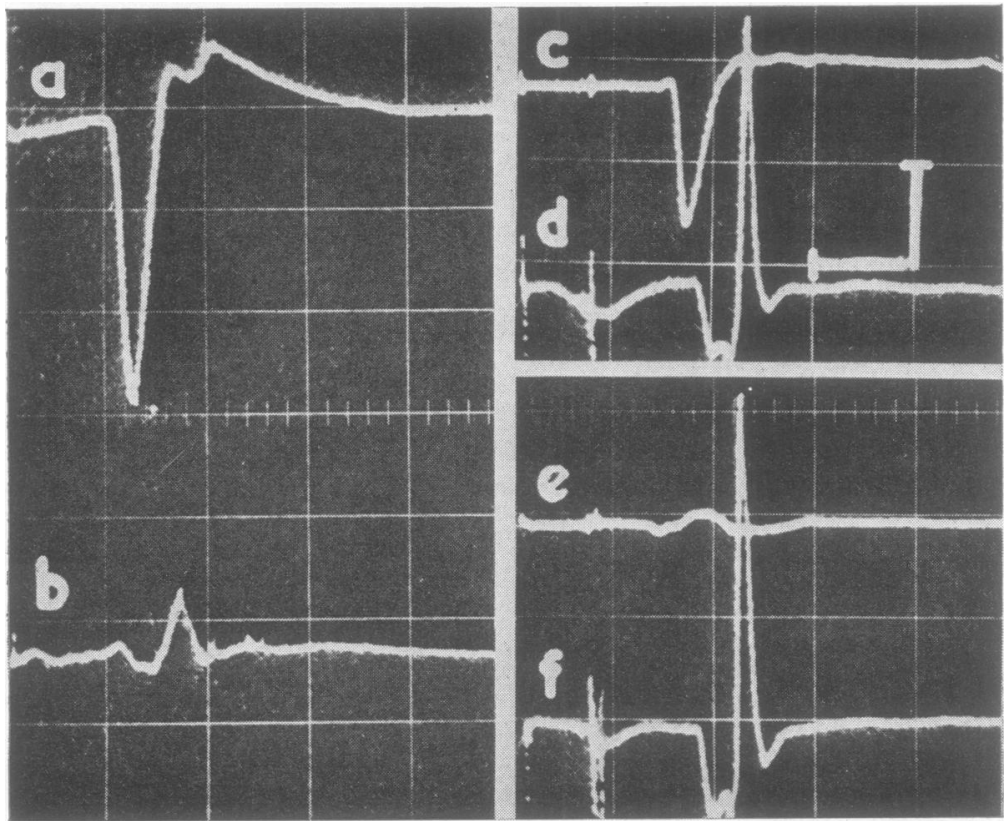

FIG. 2. Calibration: Vertical $=$ $0.2 \mathrm{mV}$ for $\mathrm{c}, \mathrm{e}, 0.5 \mathrm{mV}$ for $a, b, d, f$. Horizontal $=20$ msec.

FIG. 3. Calibration: Vertical $=$ $2.0 \mathrm{mV}$ for $a$ and $d, 0.5 \mathrm{mV}$ for $b, c, e$, and $f$. Horizontal $=5$ msec.

FIG. 2. Procaine infiltration of medial hamstrings muscle group, showing depression of indirect as well as direct hamstring jerks.

a Electromyograph of reflex from medial hamstrings muscles elicited by percussion of hamstrings tendons.

$b$ As above after infiltration of medial hamstrings bellies with $10 \mathrm{ml}$. procaine $1 \%$. The small response seen is probably field spread from the lateral hamstrings group as it differs in configuration from the original muscle potential.

c Indirect hamstrings reflex elicited by percussion of tendo Achillis, before procaine block.

d Ankle jerk before procaine block.

$e$ and $f$ As in $c$ and $d$ after infiltration of medial hamstrings group showing abolition of indirect hamstrings jerk without change in ankle jerk.
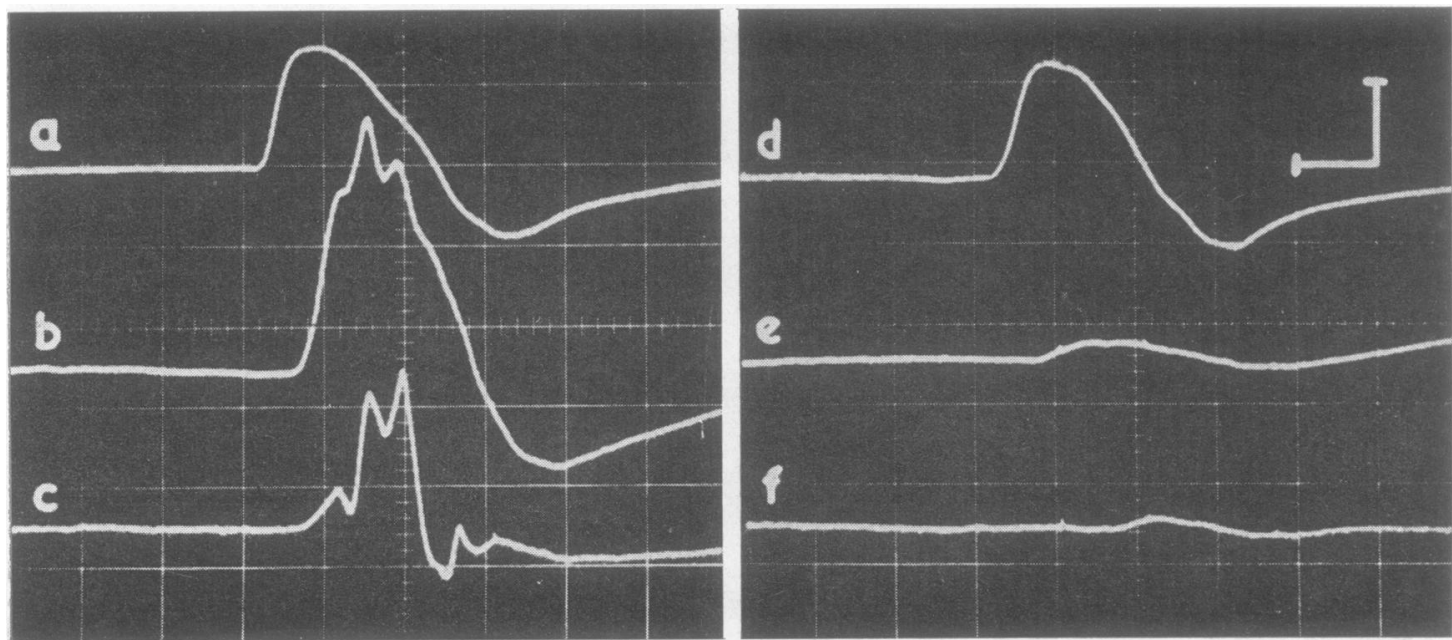

FIG. 3. Ischaemia of forearm, demonstrating preservation of indirect biceps jerk in response to percussion of radius. $a, b$, and $c$ show reflex contractions of the biceps, brachioradialis, and finger flexors in response to radial tap, $d, e$, and $f$, as above, after 30 minutes' ischaemia of forearm. Brachioradialis and finger jerks have disappeared without any change in amplitude of indirect biceps jerk. 
$26.5 \mathrm{msec}$. (mean $23.5 \mathrm{msec}$.) as can be seen in Table I. When the hamstrings jerk was produced indirectly by a blow to the tendo Achillis, the latency was 0.5 to $7.0 \mathrm{msec}$. (mean $3.0 \mathrm{msec}$.) longer. Frequently the indirect hamstrings jerk could be elicited by tapping the lateral or medial malleolus. In some patients a quadriceps response could also be obtained by percussing the malleoli.

In the upper limbs, the indirect pectoralis major, biceps, triceps, brachioradialis, and finger jerks could be obtained simultaneously by a blow to the radius, ulna or clavicle, with a latency only 1 to 4 msec. greater than that of the direct reflex produced by percussion of the muscle tendon. In one subject both biceps muscles contracted in response to a blow on either clavicle, and when the sternum was percussed both biceps responded with a latency of $16.5 \mathrm{msec}$.

PROCAINE BLOCK An indirect hamstrings jerk elicited by a blow on the tendo Achillis was demonstrated and recorded, together with the triceps surae or ankle jerk (Fig. 1) and the bellies of the gastrocnemius and soleus were then infiltrated widely with procaine. The hamstrings jerk was not diminished although the gastrocnemius contraction was greatly reduced, indicating that the indirect hamstrings jerk does not depend upon the muscle spindles of the gastrocnemius.

In another experiment the medial hamstrings bellies were infiltrated with procaine, after first recording the direct and indirect hamstrings jerks (Fig. 2). Amplitude of both direct and indirect hamstrings jerks was markedly reduced without significant loss of muscle power, monitored by E.M.G. recordings.

This experiment indicates that receptors for the indirect hamstrings jerk are the spindles in the hamstrings muscles themselves. Similarly, infiltration of the brachioradialis reduced the response of this muscle to radial tap, but did not affect the biceps or finger flexor responses. Infiltration of finger flexors grossly depressed both direct and indirect finger jerks, while the biceps and brachioradialis continued to contract on percussion of the radius.

ISCHAEMIA The indirect biceps, brachioradialis, and finger jerks were obtained by a tap on the distal end of the radius (Fig. 3). The forearm was then rendered ischaemic by a cuff just above the elbow, causing abolition of the brachioradialis and finger flexor responses while the indirect biceps jerk was preserved without significant increase in latency.

In three patients, the arterial supply to the leg was cut off by a cuff applied proximal to the knee, until the ankle jerk was abolished and sensation grossly diminished. The indirect hamstrings jerk persisted with unaltered latency, indicating that it was not dependent upon large afferent fibres from the periphery of the limb. The latency is such that the reflex could not be mediated by small afferent fibres which continued to conduct at the height of ischaemia.

REFLEX CONTRACTION WITHOUT MUSCLE STRETCH Since the foregoing experiments showed that the stimulus for indirect or 'jar' reflexes is applied directly to the belly of the muscle concerned, and the slight increase in latency over direct reflexes is consistent with the transmission of a mechanical stimulus from the point of percussion, it became of interest to see whether a brief stretch of the muscle belly was an essential requirement.

Three subjects with brisk indirect hamstrings jerks, easily elicited by a tap on the ligamentum patellae, were positioned as shown in Fig. 4, the limb being firmly clamped with the knee flexed to a right angle. The reflex was then elicited while displacement of the limb produced by percussion was measured (Fig. 5). In all experiments, movement of the tibia was in the direction of shortening, not stretching, the hamstrings muscles.

In another subject, a tap on the subcutaneous border of the ulna, $10 \mathrm{~cm}$. distal to the elbow joint (which was flexed to a right angle), consistently triggered an indirect biceps jerk. In this case, the limb was free to move, so that definite transient flexion of the elbow was produced by the blow, and this, clearly, would shorten the biceps, not stretch it.

COMPARISON OF REFLEX AND VIBRATION LATENCIES A series of recordings was made of the E.M.G. of

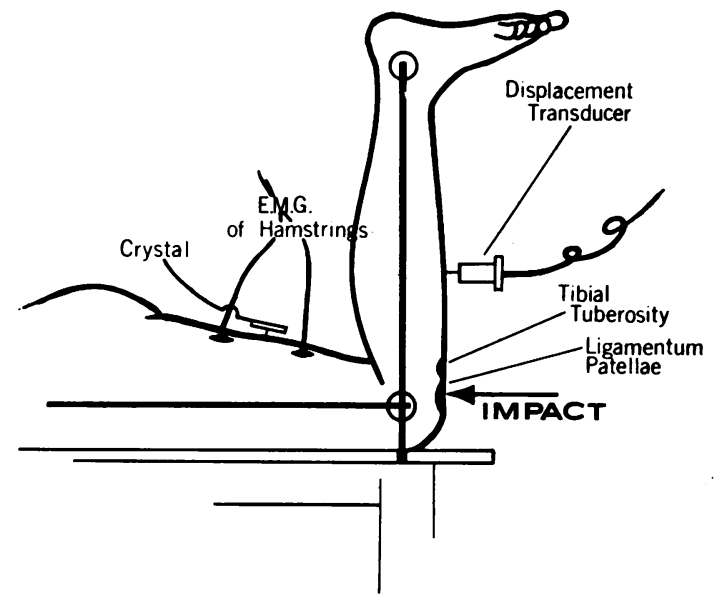

FIG. 4. Diagram of experimental arrangement to demonstrate indirect hamstrings jerk elicited by blow on the ligamentum patellae causing shortening, not lengthening, of the hamstrings muscles. 


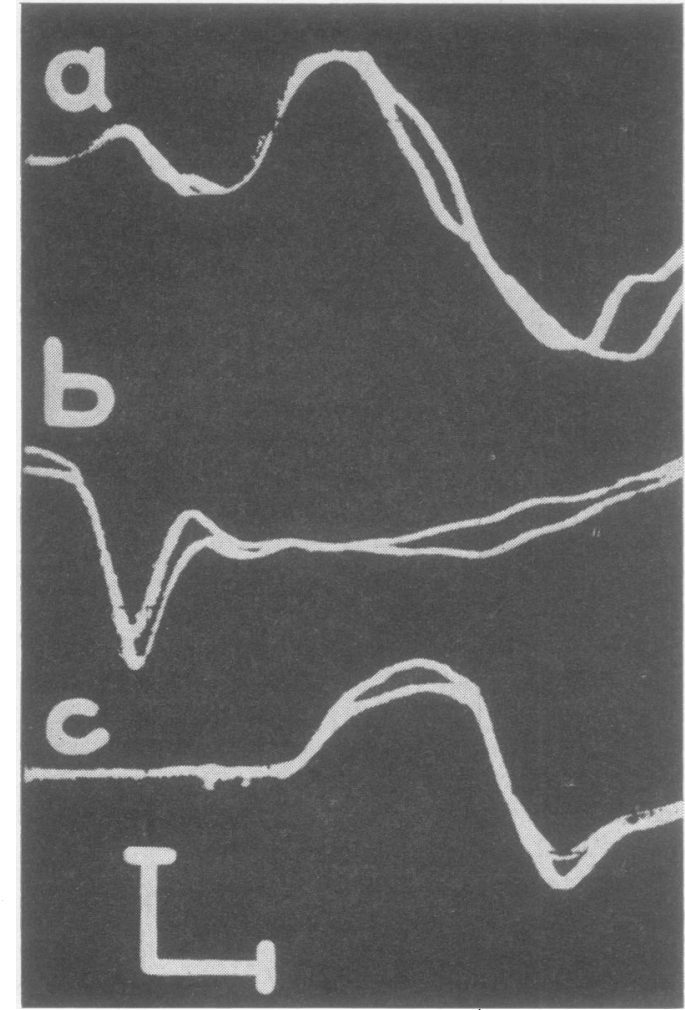

FIG. 5. Indirect hamstrings jerk, elicited with knee flexed as in Fig. 4; two consecutive reflexes superimposed. A hamstrings jerk follows a blow on the ligamentum patellae although displacement of the tibia by $0.3 \mathrm{~mm}$. indicates that the knee has been flexed, i.e., the hamstrings have shortened. a Vibration wave recorded over hamstrings muscles. $b$ Displacement of leg after impact. A downward deflection indicates movement of the tibia in the direction of flexion of the knee. $c$ Electromyograph of hamstrings. Calibration: Vertical $=b, 0.2 \mathrm{~mm}$. displacement; $c$. $0.2 \mathrm{mV}$. Horizontal $=10 \mathrm{msec}$.

the reflexly contracting muscle, and the vibration wave spreading over its belly, first when its own tendon of insertion was struck (direct reflex), and secondly when some more remote point was percussed, not directly in continuity with the muscle (indirect reflex). Records were discarded unless there was obvious clinical evidence of an indirect reflex contraction. The latencies, i.e., time from the contact of the percussion hammer to the onset of either muscle potential or vibration wave, were measured, and these are shown in Tables I and II. It will be seen that the difference in latency of direct and indirect reflexes, and the difference between time of arrival of corresponding vibration waves is comparable in each instance.
TABLE I

LATENCIES MEASURED TO THE NEAREST 0.5 MSEC.

\begin{tabular}{|c|c|c|c|c|c|c|}
\hline \multirow[b]{2}{*}{ Subject } & \multicolumn{3}{|c|}{ Hamstrings Jerk } & \multicolumn{3}{|c|}{ Vibration Wave } \\
\hline & Direct & Indirect & Difference & Direct & Indirect & Differenc \\
\hline
\end{tabular}

\begin{tabular}{llllllll}
\hline N.S. & 22.0 & 29.0 & 7.0 & 2.0 & 8.0 & 6.0 & ()
\end{tabular}

T.K. $20.0 \quad 24.0$

M.P. $\quad 23.0 \quad 26.0$

A.J. $25.0 \quad 26.5$

R.H. $26.5 \quad 27.0$

W.K. $22.0 \quad 24.5$

D.B. $23.0 \quad 27.0$

E.R. $23.0 \quad 24.5$

B.A. $\quad 25.5 \quad 27.5$

I.R. $\quad 24 \cdot 0 \quad 27 \cdot 0$

Mean $23.5 \quad 26.5$

4.0
3.0
1.5
0.5
2.5
4.0
1.5
2.0
3.0
3.0

TABLE II

LATENCIES MEASURED TO THE NEAREST 0.5 MSEC.

\begin{tabular}{|c|c|c|c|c|c|c|c|}
\hline \multirow[b]{2}{*}{ Subject } & \multicolumn{3}{|c|}{ Biceps Jerk } & \multicolumn{3}{|c|}{ Vibration Wave } & \multirow{2}{*}{$\begin{array}{l}\text { Percussion } \\
\text { Point for } \\
\text { Indirect } \\
\text { Reflex }\end{array}$} \\
\hline & Direct & $\begin{array}{l}\text { In- } \\
\text { direct }\end{array}$ & $\begin{array}{l}\text { Differ- } \\
\text { ence }\end{array}$ & Direct & $\begin{array}{l}\text { In- } \\
\text { direct }\end{array}$ & $\begin{array}{l}\text { Differ- } \\
\text { ence }\end{array}$ & \\
\hline $\begin{array}{l}\text { N.S. } \\
\text { N.S. } \\
\text { W.K. } \\
\text { I.C. } \\
\text { J.P. } \\
\text { J.P. }\end{array}$ & $\begin{array}{l}17.5 \\
17.5 \\
14.0 \\
19.0 \\
13.0 \\
13.0\end{array}$ & $\begin{array}{l}20.0 \\
19.0 \\
16.0 \\
21.5 \\
17.0 \\
14.0\end{array}$ & $\begin{array}{l}2.5 \\
1.5 \\
2.0 \\
2.5 \\
4.0 \\
1.0\end{array}$ & $\begin{array}{l}0.5 \\
0.5 \\
1.5 \\
1.0 \\
0 \\
0\end{array}$ & $\begin{array}{l}2.5 \\
2.5 \\
3.0 \\
2.5 \\
3.0 \\
1.0\end{array}$ & $\begin{array}{l}2.0 \\
2.0 \\
1.5 \\
1.5 \\
3.0 \\
1.0\end{array}$ & $\begin{array}{l}\text { Clavicle } \\
\text { Radius } \\
\text { Radius } \\
\text { Radius } \\
\text { Clavicle } \\
\text { Ulna }\end{array}$ \\
\hline
\end{tabular}

In one subject, the crossed adductor jerk, elicitefa by a tap on the opposite ligamentum patellae, hada shorter latency than the direct adductor jerk. The vibration wave also had a shorter latency, and it $8 \times 0$ likely that the time taken to compress the se्सt? tissues over the adductor magnus tendon woufd $\vec{\circ}$ explain this, since the more rigid ligamentum patella would transmit the impact more readily.

\section{DISCUSSION}

The small difference in latency between direct and $\frac{2}{\Phi}$ indirect reflexes precludes mediation of the indirect $\stackrel{\varrho}{\rightarrow}$ response by any but the largest afferent nerve fibres. Ischaemia blocks activity in large fast-conducting fibres. Since ischaemia of a limb failed to abolish the indirect reflex in a muscle separated from the point of percussion by the block, and since the latency of indirect reflexes would not permit of a? slow-conducting afferent limb, it follows that the afferent limb must arise above the block.

Procaine infiltration of a muscle depresses spindle $ᄋ$ sensitivity by temporarily inactivating the small fibre? motor supply to the spindles. Procaine infiltration $\frac{\text { ? }}{5}$ of the gastrocnemius-soleus grossly reduced the $D$ ankle jerk without affecting the indirect hamstrings jerk elicited concurrently by percussion of the tendo $\bar{N}$ Achillis. We can conclude that afferents from the muscle spindles of the triceps surae play no part in $N$ the indirect hamstrings jerk, reinforcing the evidence $\underset{\omega}{N}$ 
obtained from ischaemic block. On the other hand, procaine infiltration of the hamstrings depressed indirect as well as direct hamstrings reflexes, suggest-

- ing that indirect reflexes arise in the spindles of the muscle whose contraction comprises the indirect reflex.

How then are spindle receptors stimulated by percussion of parts remote from the muscle concerned? One possibility is transmission of a stretch stimulus by a lever action of the jointed segments of a limb. In a number of experimental situations we have produced indirect reflexes by a blow whose direction tends to shorten rather than lengthen the corresponding muscle. In addition we have recorded biceps reflexes triggered by taps on the sternum and contralateral clavicle, sites unfavourable for the transmission of a stretch stimulus.

In all cases, however, a vibration wave could be recorded over the muscle and we have shown that there is correspondence between the increase in latency of indirect reflexes compared with direct reflexes and the delay in arrival of a vibration wave produced by remote percussion compared with percussion of the muscle tendon.

Animal experiments have established that the muscle spindle is sensitive to linear stretch and to velocity of stretch (Cooper, 1961; Bessou and Laporte, 1962). Activation of the gamma efferent (fusimotor) fibres causes contraction of intrafusal muscle fibres and thus heightens sensitivity of spindle receptors to both static and dynamic stretch (Matthews, 1964). Moreover, it has been shown that muscle spindles will respond to vibration transmitted from bone if the muscle is under suitable tension (Echlin and Fessard, 1938). Granit and Henatsch (1956) showed that the sensitivity of spindle receptors to vibration was increased by activation of the gamma system from the brain-stem, or by using the pinna reflex. The application of a vibrator to a tendon was effective in exciting muscle spindles. Bianconi and Van der Meulen (1963) found that most spindle receptors responsive to vibration were those with afferents of high conduction velocity and suggested that they were nuclear bag endings.

Our findings are consistent with the hypothesis that percussion of a bone or other firm part of a limb or the trunk in man initiates a vibration wave which is propagated from bone to muscle, stimulating the receptors of any sensitive muscle spindle lying in its path to produce reflex contraction of that muscle.

This hypothesis has a number of clinical applications. If percussion of the radius is observed to initiate reflex contraction of the biceps and finger flexors as well as brachioradialis, there is no point in proceeding to elicit biceps and finger jerks separately as the reflex arcs of these muscles have already been tested. The phenomenon of 'inversion' of the supinator (radial) jerk with a lesion of the fifth and sixth cervical segments or nerve roots simply means that the biceps and brachioradialis muscles are unable to contract reflexly because their reflex arc has been interrupted, but that the finger jerk is elicited by the vibration wave in the normal way as its reflex arc is intact. The phenomenon is particularly striking when the spinal cord is compressed at the C5-6 level, rendering reflex arcs hyperactive below this level. Under these circumstances the triceps muscle as well as the finger flexors may respond briskly to a tap on the radius (or elsewhere on the upper limb) and the response to percussion of the biceps tendon becomes extension of the elbow since the biceps jerk is absent. It is probable that the Hoffmann reflex, which is associated with brisk finger jerks, results from vibration (induced by snapping the terminal phalanx of the middle finger) being transmitted to muscle spindles of the thenar eminence.

It is indeed possible that transmission of vibration along a tendon plays a more important part in eliciting the usual tendon jerk than the direct application of stretch to the muscle spindle.

\section{SUMMARY}

Reflex irradiation or spread has been studied in normal subjects and patients with brisk tendon jerks, in whom multiple 'indirect' reflexes could be elicited by percussion at points remote from the muscles responding.

The use of procaine infiltration of muscle to reduce spindle sensitivity by blocking its gamma efferent supply, and of ischaemia to block nerve conduction, demonstrated that the afferent limb of an indirect reflex arises from spindles of the muscle whose contraction comprises the indirect refiex, and not from remote receptors near the point of percussion.

Since an indirect reflex could be elicited by a blow which produced shortening of the muscle responding, it appeared unlikely that stretch was the adequate stimulus. On the other hand, the increase in reflex latency when the reflex was triggered indirectly was matched closely by the longer time required for a vibration wave to arrive at the muscle.

All findings are consistent with the hypothesis that percussion of bone or other firm part of limb or trunk initiates a vibration wave which is propagated from bone to muscle stimulating the receptors of any sensitive muscle spindle lying in its path, thereby producing a reflex contraction. 
The application of this hypothesis to common clinical phenomena is discussed.

This project was made possible by grants from the National Health and Medical Research Council of Australia and the Post-Graduate Foundation in Medicine of the University of Sydney. Ciba Co. Pty. Ltd. generously provided funds for equipment.

The authors are grateful to Mr. P. D. Neilson, electronic technician, for his assistance with these experiments. The figures were prepared by the Department of Medical Illustration, University of New South Wales.

\section{REFERENCES}

Bessou, P., and Laporte, Y. (1962). Responses from primary and secondary endings of the same neuromuscular spindle of the tenuissimus muscle of the cat. In Symposium on Muscle Receptors, edited by D. Barker, pp. 105-119. Hong Kong University Press.

Bianconi, R., and Van der Meulen, J. P. (1963). The response to vibration of the end organs of mammalian muscle spindles. J. Neurophysiol., 26, 177-190.

Cooper, S. (1961). The responses of the primary and secondary endings of muscle spindles with intact motor innervation during applied stretch. Quart. J. exp. Physiol., 46, 389-398.

Denny-Brown, D. E., and Liddell, E. G. T. (1927). Observations on the motor twitch and on reflex inhibition of the tendon-jerk of M. supraspinatus. J. Physiol. (Lond.), 63, 70-80.
Echlin, F., and Fessard, A. (1938). Synchronized impulse discharges Z from receptors in the deep tissues in response to a vibrating $\mathbb{D}$ stimulus. Ibid., 93, 312-334.

Granit, R., and Henatsch, H. D. (1956). Gamma control of dynamic properties of muscle spindles. $J$. Neurophysiol., 19, 356-366.

Hagbarth, K. E. (1962). Post-tetanic potentiation of myotatic reflexesco in man. J. Neurol. Neurosurg. Psychiat., 25, 1-10.

Lewis, T., Pickering, G. W., and Rothschild, P. (1931). Centripetal ${ }^{\top}$ paralysis arising out of arrested bloodflow to the limb. Heart, 16, 1-32.

Lombard, W. P. (1889). On the nature of the knee-jerk. J. Physiol. $\overline{\bar{\Omega}}$ (Lond.), 10, 122-148.

Magladery, J. W., McDougal, D. B., and Stoll, J. (1950). Electrophysiological studies of nerve and reflex activity in normal man. $\overrightarrow{\bar{F}}$ II. The effects of peripheral ischemia. Bull. Johns Hopk. Hosp., 86, 291-312.

- Porter, W. E., Park, A. M., and Teasdall, R. D. (1951). Electro- 으 physiological studies of nerve and refiex activity in normal man. $\bar{O}$ IV. The two-neurone reflex and identification of certain action $\overline{\bar{c}}$ potentials from spinal roots and cord. Ibid., 88, 499-519.

Matthews, P. B. C. (1964). Muscle spindles and their motor control. Q Physiol. Rev., 44, 219-288.

- and Rushworth, G. (1957a). The selective effect of procaine on the stretch reflex and tendon jerk of soleus muscle when applied to its nerve. J. Physiol. (Lond.), 135, 245-262.

- (1957b). The relative sensitivity of muscle nerve fibres to procaine. Ibid., 135, 263-269.

Rushworth, G. (1960). Spasticity and rigidity: an experimental study and review. J. Neurol. Neurosurg. Psychiat., 23, 99-118.

Sherrington, C. S. (1898). Phil. Trans. 190B. Reprinted in Selected Writings of Sir Charles Sherrington, edited by D. Denny-? Brown, p. 152. Hamish Hamilton, London. (1939). 